University of South Florida

DIGITAL COMMONS

Digital Commons @ University of

@ UNIVERSITY OF SOUTH FLORIDA

South Florida

KIP Articles

KIP Research Publications

August 2010

\title{
An Emerging Disease Causes Regional Population Collapse of a Common North American Bat Species
}

\author{
Winifred F. Frick \\ Jacob F. Pollock \\ Alan C. Hicks \\ Kate E. Langwig \\ D. Scott Reynolds
}

See next page for additional authors

Follow this and additional works at: https://digitalcommons.usf.edu/kip_articles

\section{Recommended Citation}

Frick, Winifred F.; Pollock, Jacob F.; Hicks, Alan C.; Langwig, Kate E.; Reynolds, D. Scott; Turner, Gregory G.; Butchkoski, Calvin M.; and Kunz, Thomas H, "An Emerging Disease Causes Regional Population Collapse of a Common North American Bat Species" (2010). KIP Articles. 143.

https://digitalcommons.usf.edu/kip_articles/143

This Article is brought to you for free and open access by the KIP Research Publications at Digital Commons @ University of South Florida. It has been accepted for inclusion in KIP Articles by an authorized administrator of Digital Commons @ University of South Florida. For more information, please contact digitalcommons@usf.edu. 


\section{Creator}

Winifred F. Frick, Jacob F. Pollock, Alan C. Hicks, Kate E. Langwig, D. Scott Reynolds, Gregory G. Turner, Calvin M. Butchkoski, and Thomas H Kunz 
critical to test the efficacy of specific disease prevention strategies applied not only within donor and recipient communities, but also in the realm where they intersect.

\section{References and Notes}

1. J. O. Lloyd-Smith et al., Science 326, 1362 (2009).

2. C. E. Rupprecht, C. A. Hanlon, T. Hemachudha, Lancet Infect. Dis. 2, 327 (2002).

3. V. P. Hsu et al., Emerg. Infect. Dis. 10, 2082 (2004).

4. S. Riley et al., Science 300, 1961 (2003).

5. A. Moya, E. C. Holmes, F. González-Candelas, Nat. Rev. Microbiol. 2, 279 (2004).

6. M. Anishchenko et al., Proc. Natl. Acad. Sci. U.S.A. 103, 4994 (2006).

7. H. D. Song et al., Proc. Natl. Acad. Sci. U.S.A. 102, 2430 (2005).

8. C. R. Parrish et al., Microbiol. Mol. Biol. Rev. 72, 457 (2008).

9. T. Kuiken et al., Science 312, 394 (2006).

10. J. D. Blanton, K. Robertson, D. Palmer, C. E. Rupprecht, J. Am. Vet. Med. Assoc. 235, 676 (2009).

11. D. A. Brass, in Rabies in Bats: Natural History and Public Health Implications, D. A. Brass, Ed. (Livia Press, Ridgefield, CT, 1994), pp. 151-162.

12. J. S. Smith, L. A. Orciari, P. A. Yager, Semin. Virol. 6, 387 (1995).
13. G. J. Hughes, L. A. Orciari, C. E. Rupprecht, J. Gen. Virol. 86, 1467 (2005).

14. O. R. P. Bininda-Emonds et al., Nature 446, 507 (2007).

15. Materials and methods are available as supporting material on Science Online.

16. D. M. de Vienne, M. E. Hood, T. Giraud, J. Evol. Biol. 22, 2532 (2009).

17. G. S. Gilbert, C. O. Webb, Proc. Natl. Acad. Sci. U.S.A. 104, 4979 (2007)

18. T. J. Davies, A. B. Pedersen, Proc. Biol. Sci. 275, 1695 (2008).

19. G. M. Baer, J. H. Shaddock, R. Quirion, T. V. Dam, T. L. Lentz, Lancet 335, 664 (1990).

20. S. Finke, K. K. Conzelmann, Virus Res. 111, 120 (2005).

21. For helpful discussion and comments, we thank P. Beerli, J. Davies, S. Altizer, A. Park, P. Rohani, J. Allgeier, B. Han, P. Stephens, and three anonymous reviewers. For contributing rabid bats, we thank the Arizona State Public Health Laboratory, the California Department of Public Health, the Georgia Department of Community Health, the Florida Department of Health, the Idaho Department of Health and Welfare, the Indiana State Department of Health, the University of lowa's University Hygienic Laboratory, the Mississippi State Department of Health, the New Jersey Department of Health and Senior Services, the Tennessee Department of Health, the Texas Department of State Health Services, the Virginia Consolidated Laboratory, and the Washington
State Department of Health. For providing museumvouchered bat tissues, we thank the Angelo State Natural History Collection, the Carnegie Museum of Natural History, the Centro de Investigaciones Biológicas del Noroeste, the Louisiana State University Museum of Natural Science, the Museum of Vertebrate Zoology, the U.S. National Museum of Natural History, the Royal Ontario Museum, and the University of Alaska Museum. The sequences generated in this study can be found at GenBank under accession numbers GU644641 to GU645012 and GU722925 to GU723257 (table S1). This work was supported by Association of Public Health Laboratories/Centers for Disease Control Emerging Infectious Diseases and NSF Graduate Research Fellowships to D.G.S., NSF-NIH Ecology of Infectious Disease grant 0430418 to G.F.M., and funding from the U.S. Army Engineer Research Development Center-Construction Engineering Research Laboratory and Western Michigan University to M.J.V.

\section{Supporting Online Material}

www.sciencemag.org/cgi/content/full/329/5992/676/DC1

Materials and Methods

SOM Text

Fig. S1

Tables S1 to S9

References

26 February 2010; accepted 10 June 2010

$10.1126 /$ science. 1188836

\section{An Emerging Disease Causes Regional Population Collapse of a Common North American Bat Species}

Winifred F. Frick, ${ }^{1,2 *}$ ]acob F. Pollock ${ }^{3}$ Alan C. Hicks, ${ }^{4}$ Kate E. Langwig, ${ }^{4,1}$ D. Scott Reynolds ${ }^{5,1}$ Gregory G. Turner, ${ }^{6}$ Calvin M. Butchkoski, ${ }^{6}$ Thomas H. Kunz ${ }^{1}$

White-nose syndrome (WNS) is an emerging disease affecting hibernating bats in eastern North America that causes mass mortality and precipitous population declines in winter hibernacula. First discovered in 2006 in New York State, WNS is spreading rapidly across eastern North America and currently affects seven species. Mortality associated with WNS is causing a regional population collapse and is predicted to lead to regional extinction of the little brown myotis (Myotis lucifugus), previously one of the most common bat species in North America. Novel diseases can have serious impacts on naïve wildlife populations, which in turn can have substantial impacts on ecosystem integrity.

$\mathrm{E}$ merging infectious diseases are increasingly recognized as direct and indirect agents of extinction of free-ranging wildlife (1-4). Introductions of disease into naïve wildlife populations have led to serious declines or local extinctions of different species in the

\footnotetext{
${ }^{1}$ Center for Ecology and Conservation Biology (CECB), Department of Biology, Boston University, 5 Cummington Street, Boston, MA 02215, USA. Department of Environmental Studies, University of California Santa Cruz, 1156 High Street, Santa Cruz, CA 95064, USA. ${ }^{3}$ Department of Ecology and Evolutionary Biology, University of California Santa Cruz, 1156 High Street, Santa Cruz, CA 95064, USA. " Endangered Species Unit, New York State Department of Environmental Conservation, 625 Broadway, Albany, NY 12233, USA. ${ }^{5}$ St. Paul's School, Concord, NH 03301, USA. 'Wildlife Diversity Division, Pennsylvania Game Commission, 2001 Emerton Avenue, Harrisburg, PA 16669, USA

*To whom correspondence should be addressed. E-mail: wfrick@batresearch.org
}

past few decades, including amphibians from chytridiomycosis $(5,6)$, rabbits from myxomatosis in the United Kingdom (7), Tasmanian devils from infectious cancer (3), and birds in North America from West Nile virus (8). Here we demonstrate that white-nose syndrome (WNS), an emerging infectious disease, is causing unprecedented mortality among hibernating bats in eastern North America and has caused a population collapse that is threatening regional extinction of the little brown myotis (Myotis lucifugus), a once widespread and common bat species.

WNS is associated with a newly described psychrophilic fungus (Geomyces destructans) that grows on exposed tissues of hibernating bats, apparently causing premature arousals, aberrant behavior, and premature loss of critical fat reserves $(9,10)$ (Fig. 1). The origin of WNS and its putative pathogen, G. destructans, is uncertain (9). A plausible hypothesis for the origin of this disease in North America is introduction via human trade or travel from Europe, based on recent evidence that $G$. destructans has been observed on at least one hibernating bat species in Europe (11). Anthropogenic spread of invasive pathogens in wildlife and domestic animal populations, so-called pathogen pollution, poses substantial threats to biodiversity and ecosystem integrity and is of major concern in conservation efforts $(1,2)$.

WNS has spread rapidly and now occurs throughout the northeastern and mid-Atlantic regions in the United States and in Ontario and Québec provinces in Canada and currently affects at least seven species of hibernating bats (Fig. 2). Many species of bats in temperate North America hibernate in caves and mines (12) in aggregations of up to half a million individuals in a single cave (13). In late spring, these winter aggregations typically disperse into smaller sex-segregated groups of conspecifics, when adult females form maternity colonies and adult males mostly roost alone $(14,15)$. From August to October, females and males assemble at hibernacula or swarming sites to mate before hibernating $(16,17)$. The mechanisms for the persistence and transmission of $G$. destructans during summer and fall months are unknown, but spread of the fungus to new geographic regions and to other species may result from social and spatial mixing of individuals across space and time.

During the past 4 years, WNS has been confirmed in at least 115 bat hibernacula in the United States and Canada and has spread over 1200 km from Howe Cave near Albany, New York, where it was first observed in February 
2006 (9) (Fig. 2). Decreases in bats at infected hibernacula range from 30 to $99 \%$ annually, with a regional mean of $73 \%$, and all surveyed sites have become infected within 2 years of the disease arriving in their region (Fig. 3, A to C). Such sharp declines and rapid spread raise serious concerns about the impact of WNS on the population viability of affected bat species.

We investigated the impacts of diseaseassociated mortality on the regional population of little brown myotis in the northeastern United States by comparing trends in pre- and post-WNS populations and simulating 100 years of post-WNS population dynamics to assess the consequences of the introduction of the disease for bat population viability (18). We used a population matrix model parameterized with survival and breeding probabilities estimated from 16 years (1993-2008) of mark and recapture data at a maternity site of little brown myotis (19) to estimate population growth before WNS (table S1). We also calculated geometric mean growth rates from winter count surveys of this species conducted over the past 30 years at 22 hibernacula ranging across five states in the northeastern United States to determine regional population trends before the emergence of WNS (table S2).

Deterministic population growth calculated from the population matrix model of mean vital rates was positive [yearly population growth rate $(\lambda)=1.008$ ], demonstrating that population growth was stable or increasing before the emergence of WNS. Estimates of long-term growth rates over the past 30 years indicate that $86 \%$ of hibernacula ( $n=19$ out of 22) had stable or increasing populations $(\lambda=>1)$. Regional mean growth equaled 1.07 (range: 0.98 to 1.2 ) (table S2), suggesting that the regional population was growing before WNS and that vital rates estimated from the maternity site represent regional patterns. The growth of hibernating populations over the past 30 years may be in response to conservation measures, such as protective gating of mines and caves (20), the installation of bat houses (21), and the potential amelioration of impacts from pesticides banned in the 1970s (22).

To assess the impact of disease-related mortality on population viability, we simulated population dynamics using a stochastic population model that included demographic data from both infected and susceptible (uninfected) populations (18). We performed 1000 simulations of 100 years of growth from a starting population of 6.5 million bats, using means, variances, and correlations from vital rates (19) that incorporated environmental variability (23). The probability of extinction for each year was defined as the proportion of 1000 runs for which the simulated population dropped below a quasi-extinction threshold during that year. Quasi-extinction was specified as $0.01 \%$ of the starting population (that is, 650 bats). Defining extinction thresholds at low population sizes accounts for processes such as demographic stochasticity and potential Allee effects $(23-26)$.
In the simulation model, the susceptible population retained pre-WNS vital rates estimated from the 16-year mark and recapture data (19), and infected populations were given vital rates associated with annual declines calculated from infected hibernacula where consecutive yearly counts were available $(n=22)$ (18). The increase of prevalence of WNS was estimated as the percentage of uninfected hibernacula that became infected each year (2007, $5 \% ; 2008,49 \% ; 2009,59 \%)$ and was incorporated into the simulation as the proportion of the susceptible population that becomes infected each year.

Because of the inherent uncertainty in predicting the dynamics of a recently emergent disease, we evaluated the potential for disease fadeout and its influence on population viability. We estimated annual declines for each of 3 years after infection and constructed nine a priori models to test hypotheses regarding the influence of density and time since infection on population growth rates at infected hibernacula (table S3). From these estimates, there is little evidence of densitydependent declines, although model results suggest that the rate of decline ameliorates with the time since infection (Fig. 3D and table S3). To incorporate this time amelioration effect into the simulation model, we used predicted values of population growth from a nonlinear model $[\lambda=$ $1-1.16 \times \exp (-0.31 \times t)$, where $t=$ years since infection] for each of 16 years after infection, when predicted population growth stabilized $(\lambda=$ 1) (Fig. 3D).

We simulated population growth for five scenarios related to this time amelioration effect, including declines ameliorated according to predicted values (Fig. 3D) at each yearly time step and that persisted at $45 \%$ (3rd-year actual mean), 20\% (6th-year predicted mean), $10 \%$ (8th-year predicted mean), $5 \%$ (10th-year predicted mean), and 2\% (13th-year predicted mean) per year (Fig. 4). By comparing the probabilities of extinction over 100 years for these five scenarios, we evaluated the vulnerability of the regional population to extinction,

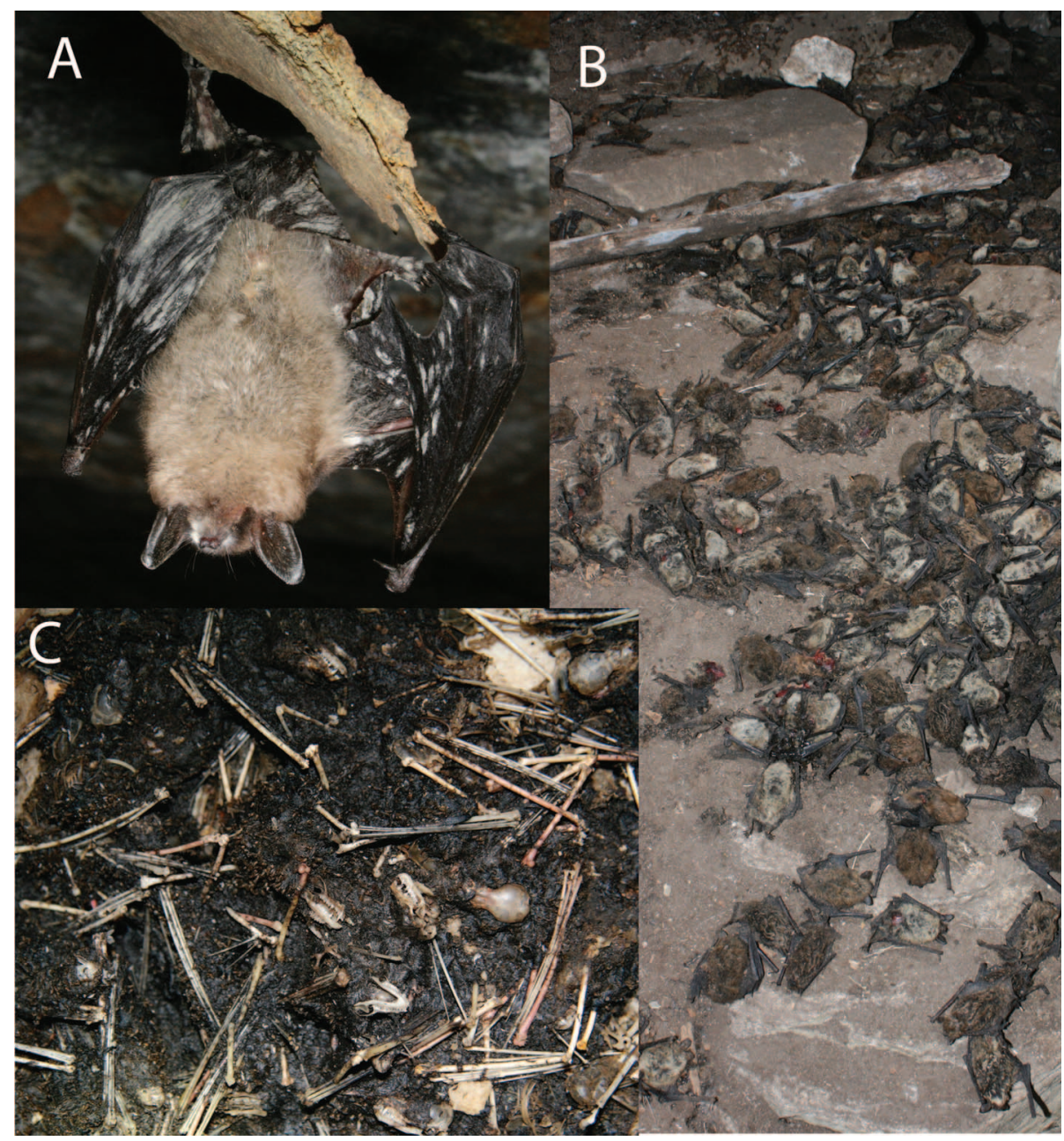

Fig. 1. (A) Photograph of hibernating little brown myotis infected with WNS. White fungus is visible on wings, ears, muzzle, and other exposed skin tissues. [Photo: Ryan Von Linden] (B) Bat carcasses piled on a cave floor, illustrating mass mortality at hibernacula infected with WNS. [Photo: Alan Hicks] (C) Skulls, bones, and decomposed carcasses covering the cave floor after multiple years of infection. [Photo: Marianne Moore] 


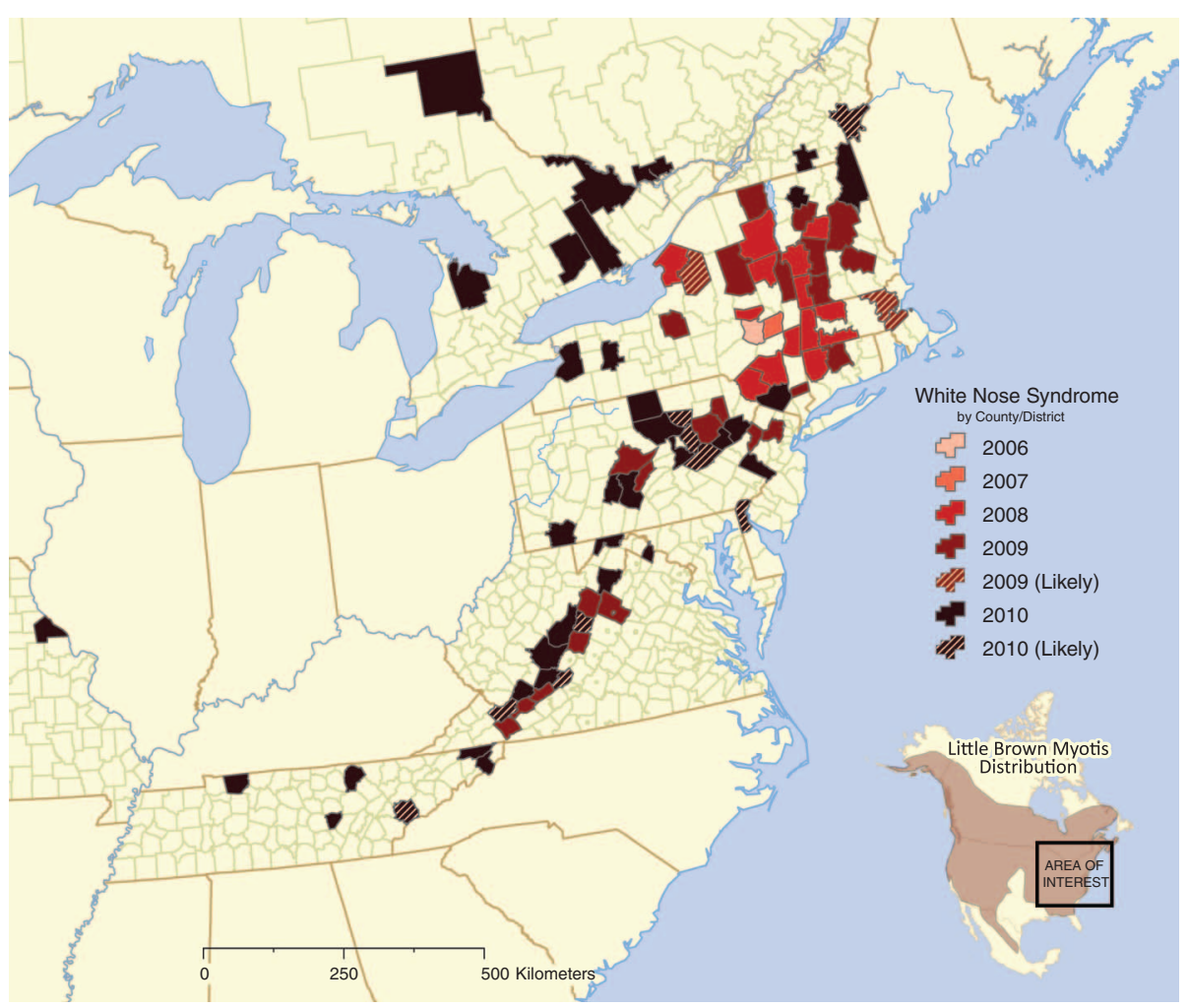

Fig. 2. Map of current distribution and spread of WNS across eastern North America.

Fig. 3. (A to $\mathbf{C})$ Population trends of little brown myotis over the past 30 years at $(A)$ small $(<1500$ bats), (B) medium ( $<5000$ bats), and (C) large (>5000 bats) hibernating colonies in the northeastern United States. Solid lines represent sites with bats infected with WNS; dotted lines represent uninfected sites. Hibernacula infected with WNS experienced a significant reduction in numbers as compared to the lowest available count from the past 30 years (Wilcoxon test $=190 ; P<0.002$ ). Large decreases in winter counts at a few hibernacula in the mid-1990s were related to winter flood events. (D) Population growth $(\lambda)$ at hibernacula (black circles) by year since infection. The curved fitted line represents the nonlinear time-dependent model, showing amelioration of mortality from WNS until population growth reaches equilibrium at $\lambda=1$ in 16 years since the first year of infection (vertical dotted line). The hockey-stick line represents declines from WNS persisting at the third-year mean of $45 \%$ per year, after a first-year decline of $85 \%$ and a second-year decline of $62 \%$.
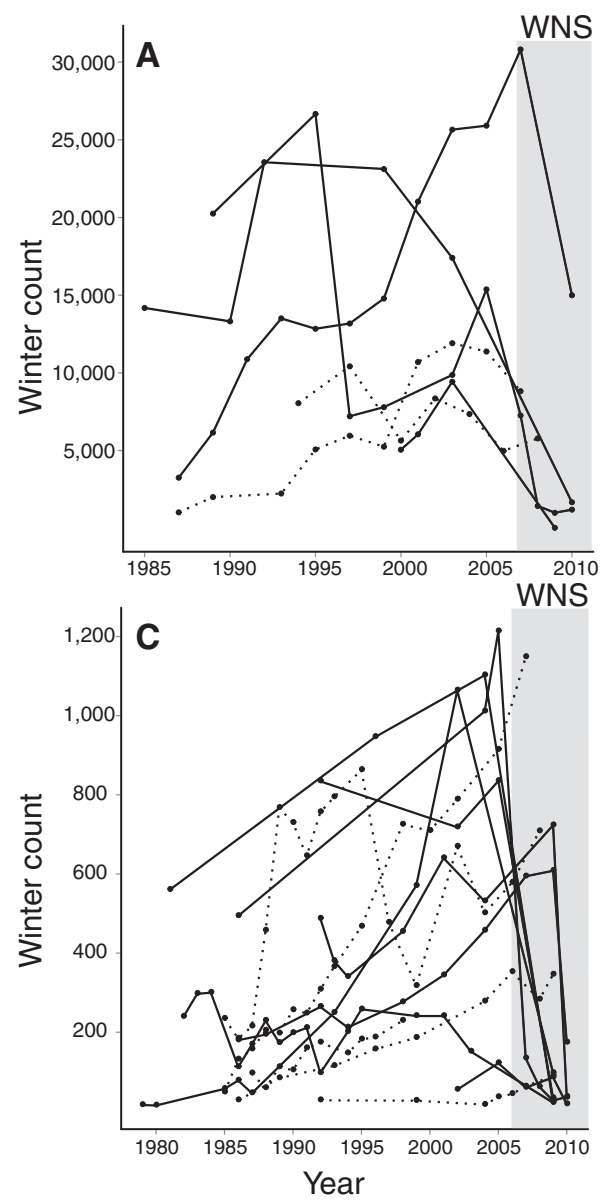

given the uncertainty in how declines from disease mortality may persist in the future.

Using vital rates derived from mean declines in the first 3 years of infection and persisting at the observed third-year mean decline of $45 \%$ per year thereafter (Fig. 3D), we expect a $99 \%$ chance of regional extinction of little brown myotis within the next 16 years (Fig. 4A). If declines continue to ameliorate with time since infection, timelines to probable extinction lengthen but remain greater than $90 \%$ by 65 years, even if declines ameliorate and stabilize at $10 \%$ per year (Fig. 4A). Model results indicate that annual declines from WNS would have to ameliorate to less than $5 \%$ per year to significantly reduce the chance of extinction over 100 years (Fig. 4A). Even if disease mortality lessens over time, the regional population is expected to collapse from an estimated starting population of 6.5 million bats to fewer than 65,000 (1\% of the pre-WNS population) in less than 20 years (Fig. 4B).

Our results paint a grim picture of a oncehealthy population of an abundant and widely distributed species now experiencing unprecedented losses from WNS and facing a serious threat of regional extinction within the next 16 years (Fig. 4). Such a severe population decline, especially if the disease spreads farther south and west of its current distribution in eastern North America, may result in unpredictable changes in ecosystem
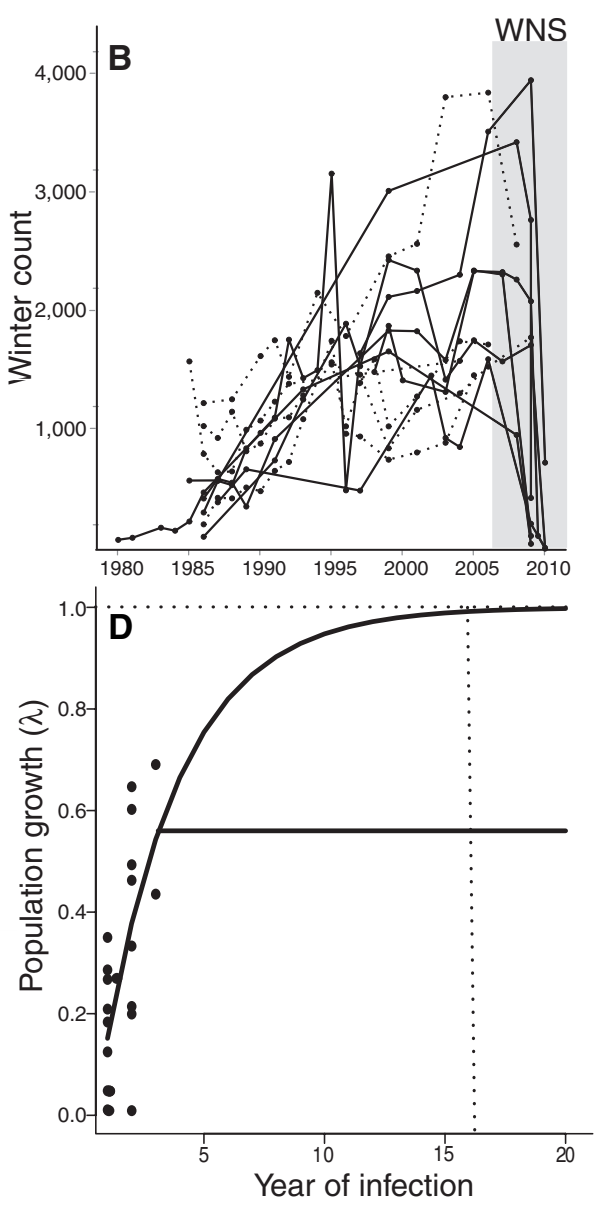
A

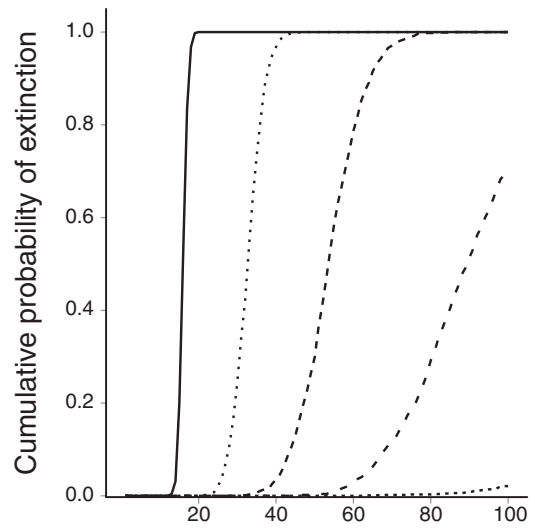

B

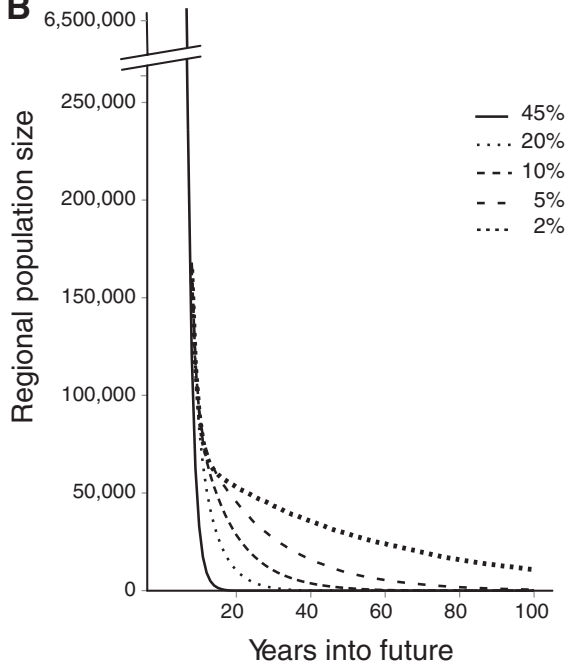

Fig. 4. (A) Cumulative probability of regional extinction of little brown myotis for five scenarios of time-dependent amelioration of disease mortality from WNS, based on matrix model simulation results. Each scenario represents predicted time-dependent declines for a specified number of years after infection and then holds the decline rate constant at either $45,20,10,5$, or $2 \%$ to demonstrate the impact of amelioration on the probability of extinction over the next 100 years. (B) Population size in each year averaged across 1000 simulations for each of the five scenarios of time-dependent amelioration of mortality from WNS.

structure and function $(27,28)$. The rapid geographic spread of WNS since 2006, coupled with the severity and rapidity of population declines, support the hypothesis of introduction of a novel pathogen into a naïve population and demonstrate the seriousness of pathogen pollution as a conservation issue (1). Our analysis focused on little brown myotis in the northeastern United States, but several other bat species are experiencing similar mortality from WNS and may also be at significant risk of population collapse or extinction. This rapid decline of a common bat species from WNS draws attention to the need for increased research, monitoring, and management to better understand and combat this invasive wildlife disease ( 1 ).
References and Notes

1. P. Daszak, A. A. Cunningham, A. D. Hyatt, Science 287, $443(2000)$

2. H. McCallum, A. Dobson, Trends Ecol. Evol. 10, 190 (1995).

3. H. McCallum, Trends Ecol. Evol. 23, 631 (2008).

4. A. M. Kilpatrick, C. J. Briggs, P. Daszak, Trends Ecol. Evol. 25, 109 (2010).

5. L. Berger et al., Proc. Natl. Acad. Sci. U.S.A. 95, 9031 (1998).

6. K. R. Lips et al., Proc. Natl. Acad. Sci. U.S.A. 103, 3165 (2006).

7. F. Fenner, FEMS Microbiol. Rev. 24, 123 (2000).

8. S. L. LaDeau, A. M. Kilpatrick, P. P. Marra, Nature 447, 710 (2007)

9. D. S. Blehert et al., Science 323, 227 (2009).

10. A. Gargas, M. T. Trest, M. Christensen, T. J. Volk, D. S. Bleher, Mycotaxon 108, 147 (2009).

11. S. J. Puechmaille et al., Emerg. Infect. Dis. 16, 290 (2010).

12. T. J. O'Shea, M. A. Bogan, Monitoring Trends in Bat Populations of the United States and Territories: Problems and Prospects (Biological Resources Discipline, Information and Technology Report USGS/BRD/ITR-2003-003, U.S. Geological Survey, Washington, DC, 2003).

13. R. Barbour, W. Davis, Bats of America (Univ. Press of Kentucky, Lexington, KY, USA, 1969).

14. T. H. Kunz, L. F. Lumsden, in Bat Ecology, T. H. Kunz, M. B. Fenton, Eds. (Univ. of Chicago Press, Chicago, IL, 2003), pp. 3-89.

15. T. H. Kunz, D. S. Reynolds, in (12), pp. 9-20.

16. W. H. Davis, H. B. Hitchcock, ]. Mammal. 46, 296 (1965).

17. D. W. Thomas, M. B. Fenton, R. M. R. Barclay, Behav. Ecol. Sociobiol. 6, 129 (1979).

18. Information on materials and methods is available on Science Online.

19. W. F. Frick, D. S. Reynolds, T. H. Kunz, J. Anim. Ecol. 79, 128 (2010)

20. E. T. Posluszny, C. Butchkoski, in Proceedings of Bat Conservation and Mining: A Technical Interactive Forum (Bat Conservation International and U.S. Department of the Interior, Office of Surface Mining, St. Louis, MO, 2000), pp. 159-168.

21. M. D. Tuttle, D. Hensley, Bats 11, 3 (1993).
22. K. N. Geluso, J. S. Altenbach, D. E. Wilson, Science 194, 184 (1976)

23. W. F. Morris, D. F. Doak, Quantitative Conservation Biology: Theory and Practice of Population Viability Analysis (Sinauer, Sunderland, MA, 2002).

24. F. Courchamp, T. Clutton-Brock, B. Grenfell, Trends Ecol. Evol. 14, 405 (1999).

25. P. A. Stephens, W. J. Sutherland, Trends Ecol. Evol. 14, 401 (1999).

26. F. Courchamp, B. Grenfell, T. Clutton-Brock, Proc. Biol. Sci. 266, 557 (1999).

27. K. J. Gaston, Science 327, 154 (2010).

28. G. W. Luck, G. C. Daily, P. R. Ehrlich, Trends Ecol. Evol. 18, 331 (2003).

29. Funding was provided by grants from the U.S. Fish and Wildlife Service (USFWS) to W.F.F., J.F.P., D.S.R., T.H.K., and G.G.T. We thank three anonymous reviewers, ]. P. Hayes, and D. F. Doak for helpful reviews and A. M. Kilpatrick for fruitful discussion. Funding for winter counts of bats at hibernacula was provided by USFWS Section 6 and State Wildlife Grants issued to the Pennsylvania Game Commission, and by Federal Aid in Wildlife Restoration Grant WE-173-G issued to the New York State Department of Environmental Conservation. Count data from hibernating colonies were kindly provided by the Connecticut Department of Environmental Protection; the Pennsylvania Game Commission; the New York Department of Environmental Conservation; Vermont Fish and Game; the Massachusetts Division of Fisheries and Wildlife; and K. Berner, State University of New York at Cobleskill. We are grateful to the many individuals who were involved in conducting annual counts of bats at hibernacula over the past 30 years. Data are available upon request from the authors.

\section{Supporting Online Material}

wWw.sciencemag.org/cgi/content/full/329/5992/679/DC1

Materials and Methods

Figs. $\mathrm{S} 1$ and $\mathrm{S2}$

Tables S1 to S3

References

22 February 2010; accepted 24 May 2010

$10.1126 /$ science 1188594

\title{
Sex-Specific Parent-of-Origin Allelic Expression in the Mouse Brain
}

\author{
Christopher Gregg, ${ }^{1,2}$ Jiangwen Zhang, ${ }^{3}$ James E. Butler, ${ }^{1,2}$ David Haig, ${ }^{4}$ Catherine Dulac ${ }^{1,2 *}$
}

Genomic imprinting results in preferential gene expression from paternally versus maternally inherited chromosomes. We used a genome-wide approach to uncover sex-specific parent-of-origin allelic effects in the adult mouse brain. Our study identified preferential selection of the maternally inherited X chromosome in glutamatergic neurons of the female cortex. Moreover, analysis of the cortex and hypothalamus identified 347 autosomal genes with sex-specific imprinting features. In the hypothalamus, sex-specific imprinted genes were mostly found in females, which suggests parental influence over the hypothalamic function of daughters. We show that interleukin-18, a gene linked to diseases with sex-specific prevalence, is subject to complex, regional, and sex-specific parental effects in the brain. Parent-of-origin effects thus provide new avenues for investigation of sexual dimorphism in brain function and disease.

$\mathrm{G}$ enomic imprinting is an epigenetic mode of gene regulation involving preferential expression of the paternally or maternally inherited allele (1). Sexual dimorphism is a central characteristic of mammalian brain function and behavior that influences major neurological diseases in humans (2). Here we address the potential existence of differential genomic imprinting in the brain according to the sex of individuals. Imprinting refers to gene expression differences between maternal and paternal chro- mosomes (3) and is also used more strictly to define complete allele-specific silencing (4). Our analysis encompasses sex differences in parent-

${ }^{1}$ Department of Molecular and Cellular Biology, Harvard University, Cambridge, MA 02138, USA. ${ }^{2}$ Howard Hughes Medical Institute, Harvard University, Cambridge, MA 02138, USA. ${ }^{3}$ FAS Research Computing, Harvard University, Cambridge, MA 02138, USA. ${ }^{4}$ Department of Organismic and Evolutionary Biology, Harvard University, Cambridge, MA 02138, USA.

*To whom correspondence should be addressed. E-mail: dulac@fas.harvard.edu 